\title{
Attributing Causes of 2015 Record Minimum Sea-Ice Extent in the Sea of Okhotsk ${ }^{\circ}$
}

\author{
Seungmok Paik, Seung-Ki Min, And Yeon-HeE Kim \\ Division of Environmental Science and Engineering, Pohang University of Science and Technology, \\ Pohang, Gyeongbuk, South Korea \\ BAEK-MIN KIM \\ Korea Polar Research Institute, Incheon, South Korea \\ HideO SHIOGAMA \\ National Institute for Environmental Studies, Tsukuba, Japan \\ JOONGHYEOK HEO \\ University of Michigan, Ann Arbor, Michigan
}

(Manuscript received 10 August 2016, in final form 9 March 2017)

\begin{abstract}
In 2015, the sea ice extent (SIE) over the Sea of Okhotsk (Okhotsk SIE) hit a record low since 1979 during February-March, the period when the sea ice extent generally reaches its annual maximum. To quantify the role of anthropogenic influences on the changes observed in Okhotsk SIE, this study employed a fraction of attributable risk (FAR) analysis to compare the probability of occurrence of extreme Okhotsk SIE events and long-term SIE trends using phase 5 of the Coupled Model Intercomparison Project (CMIP5) multimodel simulations performed with and without anthropogenic forcing. It was found that because of anthropogenic influence, both the probability of extreme low Okhotsk SIEs that exceed the 2015 event and the observed long-term trends during 1979-2015 have increased by more than 4 times (FAR $=0.76$ to 1 ). In addition, it is suggested that a strong negative phase of the North Pacific Oscillation (NPO) during midwinter (JanuaryFebruary) 2015 also contributed to the 2015 extreme SIE event. An analysis based on multiple linear regression was conducted to quantify relative contributions of the external forcing (anthropogenic plus natural) and the NPO (internal variability) to the observed SIE changes. About $56.0 \%$ and $24.7 \%$ of the 2015 SIE anomaly was estimated to be attributable to the external forcing and the strong negative NPO influence, respectively. The external forcing was also found to explain about $86.1 \%$ of the observed long-term SIE trend. Further, projections from the CMIP5 models indicate that a sea ice-free condition may occur in the Sea of Okhotsk by the late twenty-first century in some models.
\end{abstract}

\section{Introduction}

Arctic sea ice has been melting at an accelerating rate (Meier et al. 2007; Comiso et al. 2008). The Arctic regions have been the focus of many climate change studies, since climate signals are expected to be

Supplemental information related to this paper is available at the Journals Online website: http://dx.doi.org/10.1175/ JCLI-D-16-0587.s1.

Corresponding author: Seung-Ki Min, skmin@postech.ac.kr amplified by ice and snow albedo feedback over Arctic regions (Holland and Bitz 2003). The Arctic sea ice extent (SIE) decline has been largely attributed to anthropogenic influence (Hegerl et al. 2007; Min et al. 2008). Wang and Overland $(2009,2012)$ suggested that Arctic sea ice will continue to melt and that nearly icefree conditions may be observed in summers by the 2030s. Also, considerable regional sea ice loss during summer or winter was projected by Overland and Wang (2007). Further, Stroeve et al. (2007) suggested that sea ice melting in the Arctic may occur faster than model projections. 
Recently, Zhang and Knutson (2013) explored the role of anthropogenic forcing in the extreme low summer Arctic SIE of 2012. They found detectable human influence in the unprecedented low September Arctic SIE for that year and a declining trend for 2001-12. The likelihood of the occurrences was higher in the forced plus internal variability experiments than it was in the pure internal variability cases.

The SIE in the Sea of Okhotsk (Okhotsk SIE) is at its annual maximum during February-March (FM, defined as late winter). A record-breaking low SIE over the satellite observation period (since 1979) was seen in 2015. Previous studies have revealed that sea ice concentration changes in the Sea of Okhotsk may have great implications for atmospheric and oceanic conditions. Honda et al. (1999) showed that sea ice melting in the Okhotsk Sea causes anomalous heat fluxes at the ocean surface and the propagation of stationary Rossby waves, influencing global atmospheric circulations. It has also been suggested that Northern Hemispheric storm tracks are influenced by sea ice concentration variability in the Sea of Okhotsk (Mesquita et al. 2011). Further, Nakanowatari et al. (2007) suggested that the decrease in production of dense shelf water and dissolved oxygen levels and the corresponding weakened overturning in the northwestern North Pacific are caused by the sea ice melting trend in the Sea of Okhotsk.

In terms of the atmospheric forcing affecting sea ice concentration in this region, previous studies suggested that intensity changes in the Aleutian low and Siberian high can affect the variability of sea ice in the Okhotsk Sea (Parkinson 1990; Tachibana et al. 1996). Also, Ogi et al. (2004) suggested that North Atlantic Oscillation could possibly influence the Okhotsk SIE. Sasaki et al. (2007) revealed that the atmospheric conditions during late autumn and winter strongly influence late winter sea ice variability in the Okhotsk Sea. They also found that sea ice concentration variations on the interannual time scale are influenced more by winter atmospheric conditions than autumn ones. Further, Linkin and Nigam (2008) found that the North Pacific Oscillation (NPO)-west Pacific teleconnection pattern has an influence on the sea ice concentration over the Okhotsk Sea through horizontal wind and temperature advection changes.

In this study, we explored the causes of the record low Okhotsk SIE during 2015 FM using CMIP5 multimodel simulations. Particularly, we examined whether such a large reduction in Okhotsk SIE could be induced by anthropogenic warming. For this, we conducted a quantitative attribution analysis of 2015 Okhotsk SIE in the context of climate change. Since extreme events could occur due to the compound effects of anthropogenic forcing and natural internal variabilities, we investigated the role of North Pacific atmospheric circulation conditions on the extreme 2015 Okhotsk SIE anomaly, focusing on the NPO. Further, we calculated the contribution of each (external and internal) factor to the observed anomalies in the extreme event and long-term trend. Finally, we diagnosed possible future changes in the Okhotsk SIE to anticipate the arrival time of ice-free conditions depending on different greenhouse gas emission scenarios, which may have important implications on the whole Arctic SIE.

Section 2 describes observation and simulation datasets and analysis methods. In section 3, the results of the quantitative attribution analysis are explained. The possible role of natural internal variability, contribution of different factors, and future projections are also presented. Conclusions and discussions are given in section 4.

\section{Data and methods}

The satellite dataset of Goddard NT (Cavalieri et al. 1996) during 1979-2015 was used as sea ice fraction observations, which was produced using the NASATeam algorithm at the National Aeronautics and Space Administration (NASA) Goddard Space Flight Center. After selecting grids of the Sea of Okhotsk, following the domain of Overland and Wang (2007), the total area of grid points that had a sea ice concentration greater than $15 \%$ was collectively defined as the Okhotsk SIE for each month. We used sea level pressure (SLP), obtained from the National Centers for Environmental Prediction (NCEP)-National Center for Atmospheric Research (NCAR) reanalysis (Kalnay et al. 1996). For surface air temperature, we used the observational dataset from the NASA Goddard Institute for Space Studies (GISS; Hansen et al. 1999).

Multimodel datasets of phase 5 of the Coupled Model Intercomparison Project (CMIP5; Taylor et al. 2012) experiments were used to assess the extent of anthropogenic influence on the observed changes. First, we used the historical (ALL) simulations, which were integrated with both anthropogenic and natural external forcing, for 1979-2005 and the RCP (representative concentration pathway) 4.5 scenario simulations (which correspond to a nominal $4.5 \mathrm{~W} \mathrm{~m}^{-2}$ anthropogenic forcing up to 2100) for 2006-15. We defined these historical-RCP4.5 datasets for 1979-2015 as ALL_P1, and they represent the current climate (real world). To represent a counterfactual world, historical simulations for 1860-96 were defined as ALL_P0, and the anthropogenic influence on them were assumed to be 
TABLE 1. List of CMIP5 model simulations used in this study. Numbers represent number of ensemble members. (Expansions of acronyms are available online at http://www.ametsoc.org/PubsAcronymList.)

\begin{tabular}{|c|c|c|c|c|}
\hline Model & ALL_P1 & ALL_P0 & NAT_P1 & GHG_P1 \\
\hline ACCESS1.0 & 1 & 1 & - & - \\
\hline ACCESS1.3 & 1 & 3 & - & - \\
\hline BCC-CSM1.1 & 1 & 3 & 1 & 1 \\
\hline BCC-CSM1.1-m & 1 & 3 & - & - \\
\hline CanCM4 & 10 & - & - & - \\
\hline CanESM2 & 5 & 5 & 5 & 5 \\
\hline CCSM4 & 6 & 6 & - & - \\
\hline CESM1-BGC & 1 & 1 & - & - \\
\hline CESM1-CAM5 & 3 & 3 & - & - \\
\hline CESM1-CAM5.1-FV2 & - & 4 & - & - \\
\hline CESM1-FASTCHEM & - & 3 & - & - \\
\hline CESM1-WACCM & 3 & 1 & - & - \\
\hline CMCC-CESM & - & 1 & - & - \\
\hline CMCC-CM & 1 & 1 & - & - \\
\hline CMCC-CMS & 1 & 1 & - & - \\
\hline CNRM-CM5 & 1 & 10 & 6 & 6 \\
\hline CNRM-CM5.2 & - & 1 & - & - \\
\hline CSIRO-Mk3.6.0 & 10 & 1 & 5 & 5 \\
\hline EC-EARTH & 10 & 11 & - & - \\
\hline FGOALS-g2 & 1 & 4 & - & - \\
\hline FIO-ESM & 3 & 3 & - & - \\
\hline GFDL-CM2p1 & 10 & - & - & - \\
\hline GFDL-CM3 & 3 & 5 & - & - \\
\hline GFDL-ESM2G & 1 & - & - & - \\
\hline GFDL-ESM2M & 1 & - & - & - \\
\hline GISS-E2-H & 5 & 6 & 5 & 5 \\
\hline GISS-E2-H-CC & 1 & 1 & - & - \\
\hline GISS-E2-R & 6 & 6 & 5 & 5 \\
\hline GISS-E2-R-CC & 1 & 1 & - & - \\
\hline HadCM3 & 10 & 10 & - & - \\
\hline HadGEM2-AO & 1 & 1 & - & - \\
\hline HadGEM2-CC & - & 1 & - & - \\
\hline HadGEM2-ES & 1 & 4 & 4 & 4 \\
\hline INM-CM4 & 1 & 1 & - & - \\
\hline IPSL-CM5A-LR & 4 & 6 & 3 & 3 \\
\hline IPSL-CM5A-MR & 1 & 3 & 3 & - \\
\hline IPSL-CM5B-LR & 1 & 1 & - & - \\
\hline MIROC4h & 3 & - & - & - \\
\hline MIROC5 & 3 & 5 & - & - \\
\hline MIROC-ESM & 1 & 3 & - & - \\
\hline MIROC-ESM-CHEM & 1 & 1 & - & - \\
\hline MPI-ESM-LR & 3 & 3 & - & - \\
\hline MPI-ESM-MR & 3 & 3 & - & - \\
\hline MPI-ESM-P & - & 2 & - & - \\
\hline MRI-CGCM3 & 1 & 5 & - & - \\
\hline MRI-ESM1 & - & 1 & - & - \\
\hline NorESM1-M & 1 & 3 & 1 & 1 \\
\hline NorESM1-ME & 1 & 1 & - & - \\
\hline Total & 41 models & 43 models & 10 models & 9 models \\
\hline
\end{tabular}

negligible. To account for the influence of individual external forcing, we also utilized the historicalGHG experiment, which considered greenhouse gas forcing only, and the historicalNAT experiment, which had natural (solar and volcanic) forcing only, for the period of 1979-2012 (defined to GHG_P1 and NAT_P1, respectively). Further, we used two future scenario experiments of RCP4.5 and RCP8.5 (similar to RCP4.5, but with $8.5 \mathrm{~W} \mathrm{~m}^{-2}$ anthropogenic forcing up to 2100) to project future changes of the Okhotsk SIE by 2100 . All the available ensemble members were used for each experiment (Table 1). There were 123 runs for ALL_P1, 

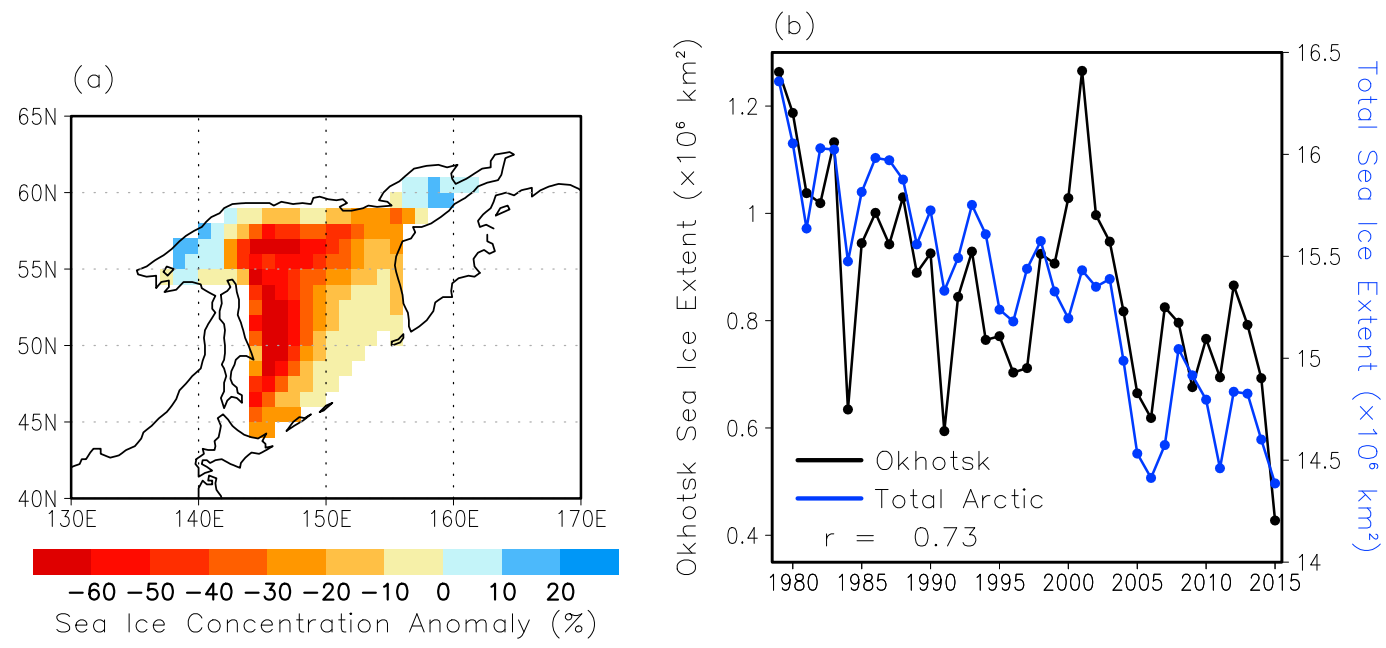

FIG. 1. (a) Observed late winter (FM) sea ice concentration anomalies in the Sea of Okhotsk (\%) during 2015, relative to the 1979-2010 mean. (b) Time series of FM Okhotsk (black) and whole Arctic (blue) sea ice extent $\left(\times 10^{6} \mathrm{~km}^{2}\right)$ for 1979-2015. Correlation coefficient $(r)$ between two time series is presented.

139 runs for ALL_P0, 38 runs for NAT_P1, and 35 runs for GHG_P1. All model datasets were interpolated onto $1^{\circ} \times 1^{\circ}$ grids using a nearest-neighbor remapping method and the SIE was calculated by applying the same method as used in the observations. The SIE anomalies from all experiments were calculated relative to the 1979-2000 average from ALL_P1 to compare the climate responses to different forcing.

To evaluate the risk of the unprecedented reduction observed in 2015 and declining trend in Okhotsk SIE, we used the fraction of attributable risk (FAR) approach (Stott et al. 2004). The FAR value is calculated as $1-\left(P_{N} / P_{A}\right)$, where $P_{A}$ is the probability of the extremes exceeding the strength of the observed event (or longterm trend) in a real-world condition due to anthropogenic influence (ALL_P1 or GHG_P1), while $P_{N}$ represents the same probability of extreme events in a counterfactual world without anthropogenic activity (ALL_P0 or NAT_P1).

We estimated the contributions from ALL (anthropogenic plus natural forcing) and the particular internal variability to the observed 2015 Okhotsk SIE anomaly and its long-term linear trend based on a linear regression method. To estimate the contribution of ALL forcing, we first regressed the observed time series of the Okhotsk SIE $(y)$ onto the multimodel mean (MME) of ALL_P1 $(x)$, such that $y=\beta x+\varepsilon$. The regressed portion $(\beta x)$ or the scaled time series of ALL_P1 MME was then considered to be an attributable change due to influence of ALL. This term was divided by the observational 2015 anomaly, or long-term trend, to estimate its contribution to the observed change as a percentage value. This method is largely consistent with previous attribution studies where model-simulated responses are scaled to fit the observations, so the attributable change is dependent not on the regression coefficient but on the shape of model responses (Bindoff et al. 2013, and references therein). To estimate the contribution of a particular internal variability, we regressed residual time series $(\varepsilon)$ onto the index of internal variability (here the NPO), and then the regressed portion was regarded as the influence of the internal climate variability. To obtain an uncertainty range of contribution from each of the factors, we repeated the above processes using each ensemble member of ALL_P1 as a pseudo-observation $\left(y^{*}\right)$. For this procedure, MME of ALL_P1 was calculated without the ensemble member used.

\section{Results}

Figure 1a shows that the Sea of Okhotsk experienced a substantially low sea ice concentration in FM of 2015. It was the lowest SIE on record for the past 37 years (Fig. 1b). Also, the SIE in the whole Arctic $\left(\mathrm{NH}, 40^{\circ}-90^{\circ} \mathrm{N}\right)$ reached a record-minimum in FM of 2015. Interestingly, the SIE in the whole Arctic was found to correlate strongly with the Okhotsk SIE $(r=0.73)$. Even with the long-term trend removed, a significant correlation still existed between them $(r=0.62)$. This indicates that the Okhotsk SIE plays a role in explaining large portion of the variability of the whole Arctic SIE during FM. In particular, total Arctic SIE would not have been a record low in 2015 without the Okhotsk SIE contribution.

The observed and modeled Okhotsk SIE anomalies are illustrated in Fig. 2a, for ALL_P1, ALL_P0, 

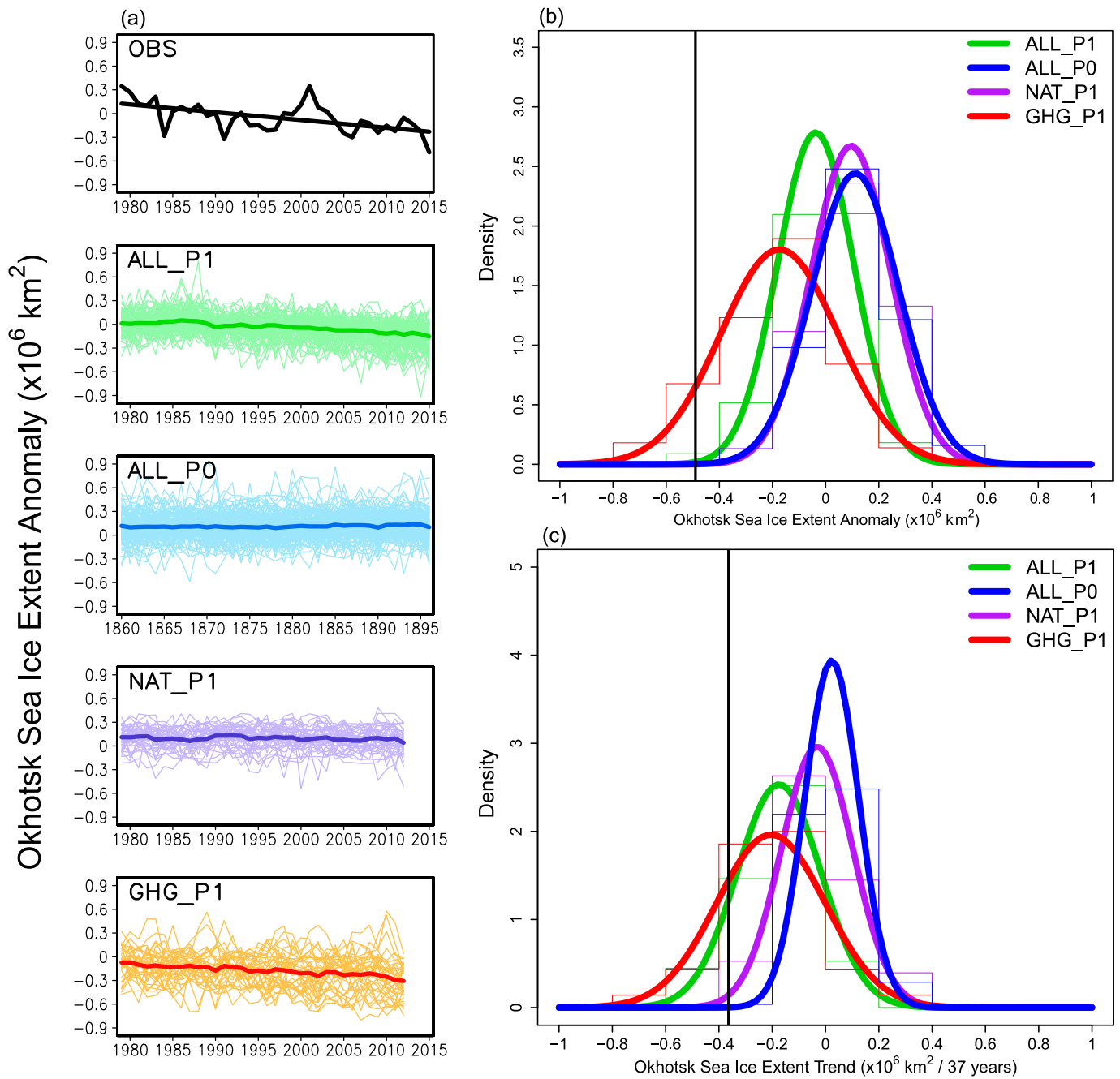

FIG. 2. (a) Late winter (FM) Okhotsk SIE anomaly time series $\left(\times 10^{6} \mathrm{~km}^{2}\right)$ from observation and CMIP5 experiments. The straight black line indicates the observed long-term linear trend. Means of the ensemble members for each experiment are indicated by thick colored lines, while thin lines indicate each simulation. (b) Normalized PDF (probability density function) for the Okhotsk SIE anomaly (all years) from ALL_P1 (green), ALL_P0 (blue), NAT_P1 (purple), and GHG_P1 (red). The vertical black line represents the observed anomaly in 2015. (c) As in (b), but for long-term linear trends (1979-2015) in Okhotsk SIE $\left[\times 10^{6} \mathrm{~km}^{2}(37 \mathrm{yr})^{-1}\right]$ from the experiments and observations.

NAT_P1, and GHG_P1. Linear long-term trends are robust in model experiments including human influences (ALL_P1 and GHG_P1), while the other experiments show very weak trends. This indicates that anthropogenic influence induces long-term decline trends in late winter Okhotsk SIE. Using probability density functions (PDFs), we compared the observed and modeled Okhotsk SIE anomalies and linear trends over whole periods (Figs. 2b,c). The PDFs of trends (Fig. 2c) were constructed with long-term linear trends of all runs available for each experiment (thin lines in Fig. 2a). Okhotsk SIE (negative) anomalies that were stronger than the observed 2015 event were found to occur very rarely without anthropogenic influence (Fig. 2b; $0.02 \%$ and $0.15 \%$ for ALL_P0 and NAT_P1, respectively; see Table 2). On the other hand, ALL_P1 $(0.64 \%)$ and GHG_P1 $(8.07 \%)$ had stronger chances of inducing a 2015-like extreme event. The FAR values were 0.76 to 1.00 , indicating that the risk of extreme low Okhotsk SIE events has increased by more than 4 times due to anthropogenic influences.

Figure 2c compares the PDFs of modeled long-term trends in Okhotsk SIE. It shows that the probability of simulated melting trends being greater than the observed trends over 1979-2015 is much greater for ALL_P1 (13.01\%) and GHG_P1 (22.86\%) than it is for 
TABLE 2. Probability of event occurrences exceeding the observed 2015 Okhotsk SIE anomaly and the long-term trend (1979-2015). FAR (P0) and FAR (NAT) represent fractional attributable risk with respect to ALL_P0 and NAT_P1 in each experiment.

\begin{tabular}{llccll}
\hline & \multicolumn{1}{c}{ Observations } & ALL_P0 & NAT_P1 & \multicolumn{1}{c}{ ALL_P1 } & \multicolumn{1}{c}{ GHG_P1 } \\
\hline 2015 late winter (FM) & $-0.49\left(\times 10^{6} \mathrm{~km}^{2}\right)$ & $0.02 \%$ & $0.15 \%$ & $0.64 \%$ & $8.07 \%$ \\
SIE anomaly & & & & FAR (P0) $=0.97$ & FAR $(\mathrm{P} 0)=1.00$ \\
& & & & FAR (NAT) $=0.76$ & FAR (NAT) $=0.98$ \\
Late winter (FM) SIE & $-0.36\left[\times 10^{6} \mathrm{~km}^{2}(37 \mathrm{yr})^{-1}\right]$ & $0 \%$ & $2.63 \%$ & $13.01 \%$ & $22.86 \%$ \\
trend (1979-2015) & & & FAR (P0) $=1.00$ & FAR (P0) $=1.00$ \\
& & & & FAR (NAT) $=0.80$ & FAR (NAT) $=0.88$ \\
\hline
\end{tabular}

ALL_P0 (0\%) and NAT_P1 (2.63\%) (see Table 2). Thus, the risk of stronger sea ice decline trends has increased by more than 5 times due to anthropogenic influence $(\mathrm{FAR} \geq 0.80)$. We conducted sensitivity tests of the FAR results to different model samples for ALL_P1 and ALL_P0. The models were divided to three groups based on the model bias in Okhotsk SIE climatology. These groups are as follows: 1) models with good performance within $\pm 20 \%$ of the observed climatology, 2) models with positive biases, and 3) models with negative biases. FAR values ( 0.91 to 1 ) were found to be very similar to results from full ensemble members. Also, the difference of the probabilities (e.g., between ALL_P1 and NAT_P1) might result from differences of the model sensitivity as well as anthropogenic influences. In this respect, we repeated our analysis using common model simulations that provide both ALL_P1 and NAT_P1 datasets and found similar FAR values (not shown). We have also checked the influence of different analysis periods by using 60-yr datasets (1956-2015 for ALL_P1 and 1860-1919 for ALL_P0) and obtained similar results (not shown).

To explore the role of atmospheric circulation on the 2015 extreme SIE event, we investigated SLP anomaly fields and surface wind vectors over the North Pacific during the midwinter [January-February (JF)] of 2015 (Fig. 3a). It shows that a strong negative NPO-like pattern exists, driving southeasterly winds into the Sea of
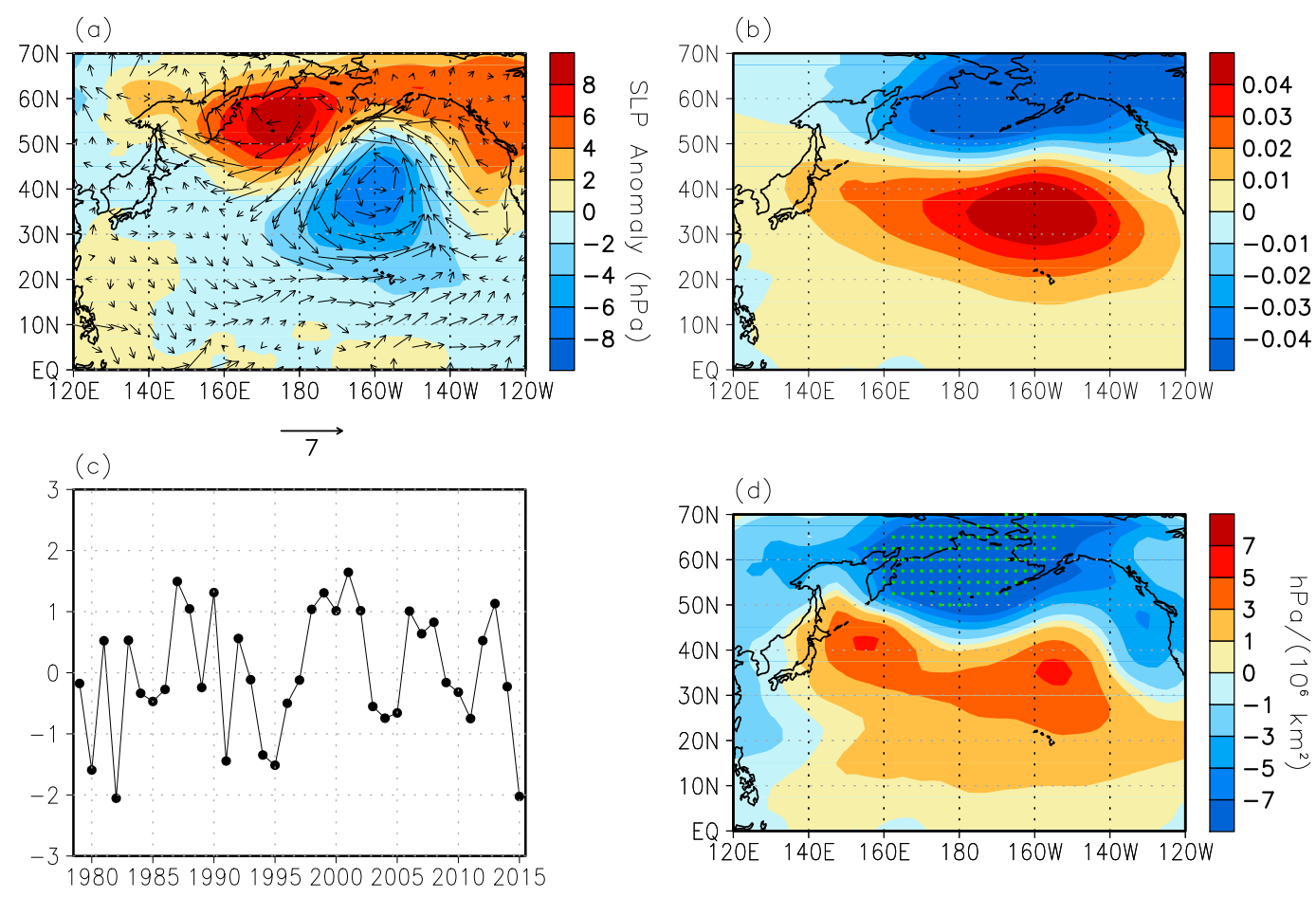

FIG. 3. (a) Observed JF (January and February average) SLP (hPa; shading) and surface wind anomaly fields ( $\mathrm{m} \mathrm{s}^{-1}$; vector) in 2015, relative to the 1979-2000 mean. (b) Spatial pattern and (c) associated temporal coefficients of the second EOF mode for JF SLP. (d) Spatial pattern of the linear regression coefficients of JF SLP over the North Pacific onto the FM Okhotsk SIE (both detrended). Green dots indicate grid boxes with statistically significant linear regression at $5 \%$ level. 
Okhotsk. Figures $3 \mathrm{~b}$ and $3 \mathrm{c}$ show the spatial pattern and associated time series of NPO, which is defined as the principal component of the second EOF mode of SLP over $0^{\circ}-70^{\circ} \mathrm{N}, 120^{\circ}-240^{\circ} \mathrm{E}$ (Rogers 1981 ). Actually, the NPO index showed an unusual large negative phase of NPO in winter 2015. When we investigated the correlations between SIE and NPO with monthly and bimonthly averaged values, maximum correlation was obtained when the NPO led the SIE by one month. Consequently, the detrended JF NPO index and FM Okhotsk SIE had the maximum, statistically significant correlation $(r=0.49)$ at the $1 \%$ level. Figure $3 \mathrm{~d}$ shows a spatial pattern of the regression coefficients of JF SLP onto FM Okhotsk SIE (both detrended). Interestingly, the positive NPO-like pattern (a spatial pattern correlation of 0.87 with the NPO pattern in Fig. 3b) was found to be robustly related to the Okhotsk SIE variability, representing that a negative phase of NPO during JF leads to the decrease in Okhotsk SIE during FM. Significant regression over the Bering Sea indicates the important role of the west-east shift of Aleutian low (Linkin and Nigam 2008).

To further explore mechanisms for the NPO-Okhotsk SIE connection, we examined the spatial correlation patterns of surface air temperature fields with the Okhotsk SIE and NPO indices after removing long-term linear trends (Fig. 4a). It indicated that negative phases of NPO induce rises in surface temperature in the southern, eastern, and northern quadrants of the North Pacific Ocean, since it accompanies cyclonic circulation arising from the tropics. Interestingly, in 2015, most of the regions had the highest or second-highest recorded temperature in the winter since 1979 , even when the longterm trend was removed (Fig. 4b). We also confirmed that the NPO had the greatest impact on the surface air temperature on the areas adjacent to the Sea of Okhotsk in simultaneous seasons, based on linear regression analysis between them (not shown). We chose a latitudelongitude area $\left(46^{\circ}-60^{\circ} \mathrm{N}, 140^{\circ}-180^{\circ} \mathrm{E}\right.$; green solid box in Fig. 4a) that had a strong correlation of the JF surface air temperature with the FM Okhotsk SIE and with the JF NPO index. The detrended area-averaged JF surface air temperature had a robust correlation with the Okhotsk SIE $(r=-0.61)$ and the NPO index $(r=-0.76)$. In addition, 2015 had the hottest recorded temperature, supporting the robust relationships (Fig. 4c). In terms of mechanism, previous studies revealed that wind vector and speed variabilities of the prevailing northwesterly winds over the Sea of Okhotsk control the Okhotsk SIE variability (Kimura and Wakatsuchi 2001; Simizu et al. 2014). Our results seem to indicate that the sea ice advance associated with northwesterly winds was weaker over the Sea of Okhotsk during 2015 JF due to the NPOdriven anomalous southeasterly wind.
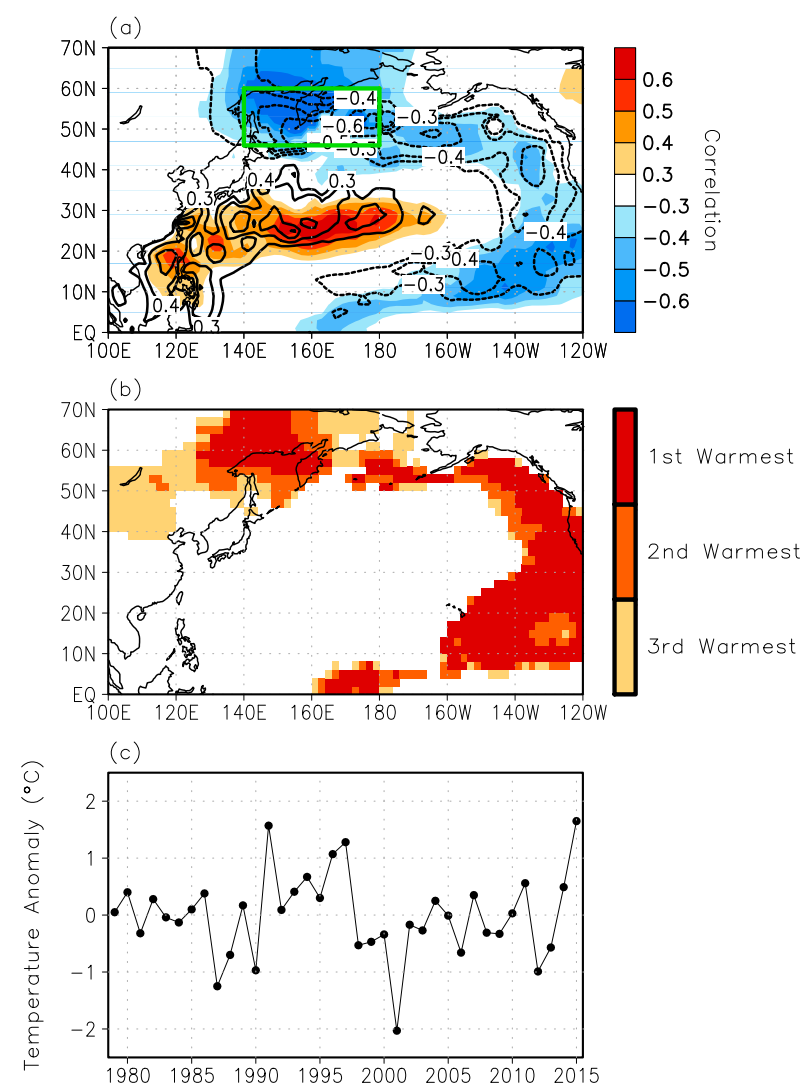

FIG. 4. (a) Spatial distribution of correlation coefficients of detrended surface air temperature with Okhotsk SIE (contour) and with NPO index (shading). The solid green box $\left(46^{\circ}-60^{\circ} \mathrm{N}\right.$, $\left.140^{\circ}-180^{\circ} \mathrm{E}\right)$ indicates areas where the temperature has large correlation coefficients with Okhotsk SIE and NPO indices. (b) Colors identify grid boxes with detrended midwinter (JF) temperatures that rank first (dark red), second (orange-red), and third (yellow-orange) warmest in 2015. (c) Time series of detrended box [solid green box in (a)] average midwinter (JF) surface air temperature anomalies $\left({ }^{\circ} \mathrm{C}\right)$ for 1979-2015.

On the other hand, although there is an overall significant influence of late autumn atmosphere condition on winter SIE as suggested by Sasaki et al. (2007), atmospheric conditions during 2014 late autumn were found to give no contribution to the 2015 winter Okhotsk SIE (not shown). In this respect, any possible connection between the NPO and the late autumn atmospheric condition and their combined impacts on the winter Okhotsk SIE warrants further investigation. NPO and Okhotsk SIE also have significant correlations with surface air temperature over the subtropical western North Pacific (Fig. 4a). This seems to be related to North Pacific Gyre Oscillation (NPGO), which is the oceanic response to NPO, and it induces substantial sea surface temperature variations in the regions (Di Lorenzo et al. 2008).

To test whether the negative NPO triggers the Okhotsk SIE reduction, we compared the Okhotsk SIE 


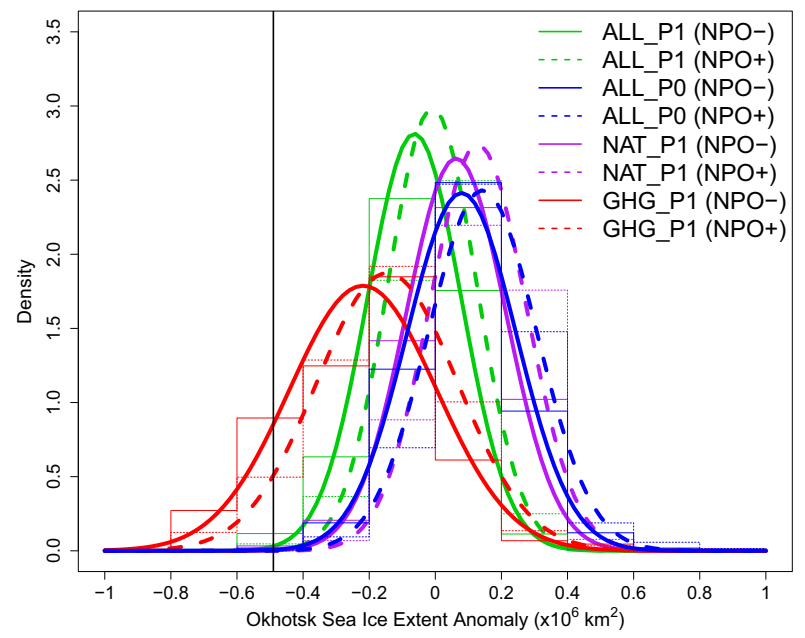

FIG. 5. Normalized PDF of late winter (FM) Okhotsk SIE anomaly $\left(\times 10^{6} \mathrm{~km}^{2}\right)$ from ALL_P1 (green), ALL_P0 (blue), NAT_P1 (purple), and GHG_P1 (red). Each experiment is divided into years that contain negative (solid) or positive (dotted) NPO phases. The vertical black line represents the observed extreme 2015 anomaly.

distributions from model simulations when NPO had positive or negative phases, following Christidis et al. (2014) (Fig. 5). For this analysis, we selected models that had similar spatial patterns of NPO to the observed (spatial correlation $r \geq 0.7$; see Table $\mathrm{S} 1$ in the online supplemental material). Since some simulations had a NPO-like spatial pattern as the first EOF mode, we investigated the first and second modes. All the experiments had stronger Okhotsk SIE reductions in the distributions of negative NPO phases (Fig. 5). The two distributions of the Okhotsk SIE anomalies for the positive and negative NPO years were significantly different at 5\% level in each experiment (based on a Kolmogorov-Smirnov test). However, it should be noted that Okhotsk SIE was still less in the cases that included anthropogenic influences but had identical NPO phases. Additionally, the NPO index does not show a significant linear trend in the long-term observations (1948-2015) as well as in most of CMIP5 forced simulations (not shown), which suggests the natural origin of the NPO variability.

We estimated the contributions of ALL (anthropogenic plus natural forcing) and the NPO influences to the observed Okhotsk SIE 2015 anomaly and long-term trend in late winter (Fig. 6). For this, we used selected models from ALL_P1, which had variabilities similar to that of the observations. Following conditions were required for the model selection. First, the NPO in the simulations should have significant spatial correlation $(r \geq 0.7)$ with the observed NPO pattern. Second, the Okhotsk SIE and NPO index in the simulations should
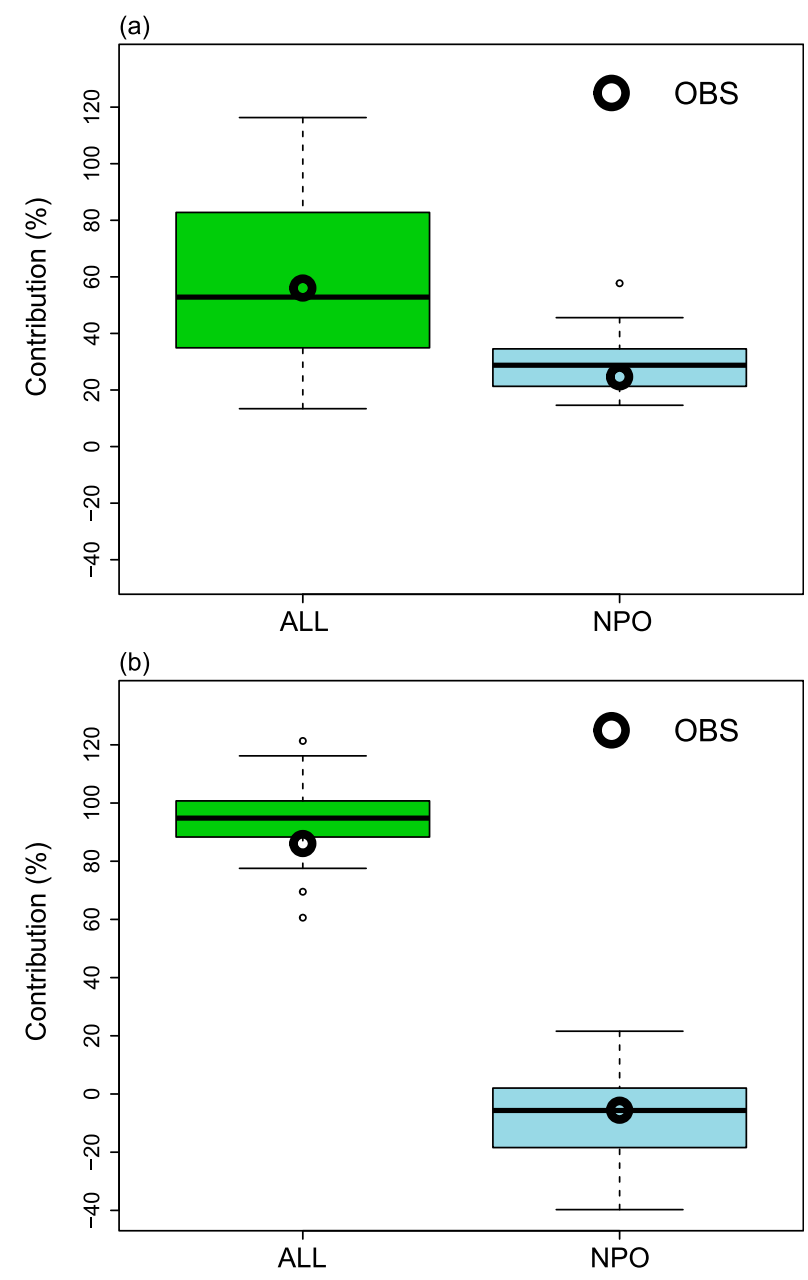

FIG. 6. Contributions of ALL forcing (anthropogenic plus natural forcing) and NPO for (a) the 2015 anomaly and (b) the longterm trend. Contributions are plotted using model samples (box and whisker) and observations (thick black open circle). Solid horizontal black lines indicate the median of model samples' contribution. For each component, only 5th to 95 th percentile values from model samples are shown.

show significant correlations at 5\% level. And third, simulations that had too small temporal variations (no change in the Okhotsk SIE over longer than $70 \%$ of the analysis period) were excluded. Also, since some simulations have much smaller linear long-term trends, we selected the runs that had trends greater than $50 \%$ of the MME trend (ALL_P1). There were 35 runs passing this requirement (Table S1). Further, when we examined the contributions to the 2015 extreme event, we selected the samples within the last 10 years (2006-15), which had a JF NPO index smaller than -1 and a normalized FM Okhotsk SIE negatively greater than $50 \%$ of the observed 2015 value. As mentioned above, we first regressed the observed time series of the Okhotsk SIE onto the multimodel mean of ALL_P1 (regression 


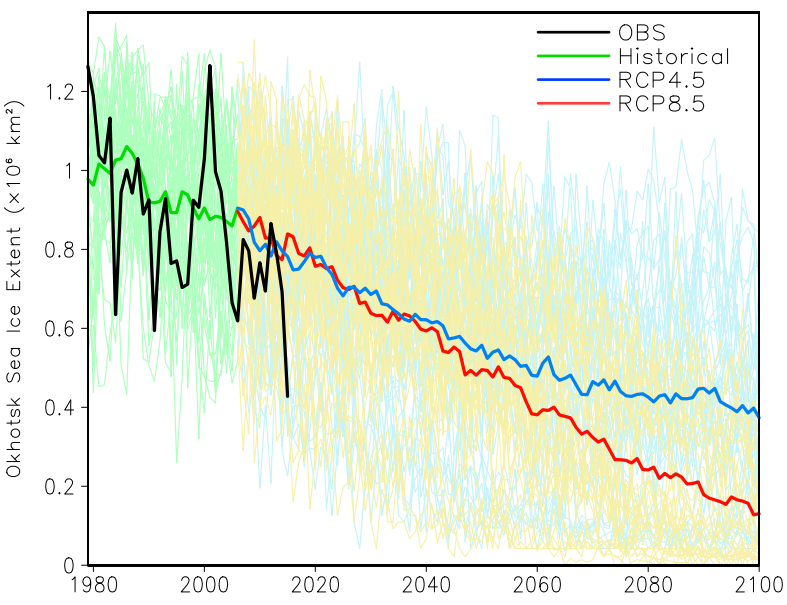

FIG. 7. Time series of late winter (FM) Okhotsk SIE $\left(\times 10^{6} \mathrm{~km}^{2}\right)$ from observations (1979-2015, black), historical (1979-2005, green), RCP4.5 (2006-2100, blue), and RCP8.5 (2006-2100, red). Thick colored lines represent the ensemble mean of each experiment, while thin lines indicate each simulation. Simulations and projections are limited to models that pass $20 \%$ bias criterion (see text for details)

coefficient $\beta=1.80)$. The regressed portion $(\beta x)$ was then considered as the contribution of ALL forcing. Similarly, to estimate the contribution of a NPO influence, we regressed residuals $(\varepsilon)$ onto the NPO index, and then the regressed portion was analyzed as the NPO contribution.

Figure 6a illustrates that ALL forcing and negative NPO contributions to the observed 2015 extreme event were about $56.0 \%$ (13.4\% to $116.3 \%)$ and $24.7 \%$ (14.6\% to $57.7 \%$ ), respectively. These were similar to the median of contributions estimated from model samples, although the results are substantially uncertain. Further, the contribution to the linear long-term trend is analyzed in Fig. 6b. It shows that ALL and NPO account for about $86.1 \%(60.6 \%$ to $121.3 \%)$ and $-5.6 \%(-39.7 \%$ to $21.6 \%)$ of the observed linear-long term trend. Especially for ALL forcing, while the contribution estimated from the observations was smaller than that of the median of simulated samples, the observed estimation lies within the ranges of simulated uncertainty. In NPO, the median of contributions estimated from model samples is similar to the observational value, while NPO has marginal impacts on long-term trends.

Finally, Fig. 7 shows FM Okhotsk SIE projections up to 2100, from two future scenarios (RCP4.5 and RCP8.5). Following Overland and Wang (2007), we limited the ensembles having the 1979-2000 mean within $\pm 20 \%$ of the observed Okhotsk SIE, since their initial conditions at the end of the twentieth century are critical to the twenty-first-century projections. Results indicate that the annual maximum extent of Okhotsk
SIE is expected to continuously decrease until 2100. Particularly, projection results from the RCP8.5 experiment suggest that the Okhotsk Sea may become sea ice free by the late twenty-first century in some models. Although the RCP4.5 experiment did not project a sea ice-free condition and had a relatively weak decline trend during the twenty-first century, the results were not conclusive since many CMIP5 models seem to underestimate the observed trend. In terms of reliability, we simply checked the influence of model skills in simulating SIE internal variability on future projections. Projection results remained unchanged when using selected ALL_P1 runs that can realistically simulate the observed interannual variability (modeled SIE standard deviation within $\pm 20 \%$ of the observed for 1979-2000 after detrending; not shown).

\section{Summary and discussion}

The Sea of Okhotsk experienced the lowest late winter (FM) SIE on record in 2015, and the SIE has been continuously decreasing over the past few decades. In this study we quantified the influence of human activity (mainly due to greenhouse gas increases) on the 2015 extreme SIE event and the long-term declining trend during 1979-2015 by comparing results from CMIP5 multimodels simulated with and without anthropogenic forcing. It was found that the probability of extreme sea ice melting events occurring in the Sea of Okhotsk, like the one in 2015, has increased by more than 4 times due to anthropogenic influence (FAR $=0.76$ to 1.00 ). Robust anthropogenic influence was also identified in the observed declining trend in the Okhotsk SIE $(\mathrm{FAR}=0.80$ to 1.00$)$

In addition to anthropogenic forcing, the possible influence of NPO, which had a strong negative phase in 2015, was examined. Interestingly, significant and maximum correlation occurred between the Okhotsk SIE and the NPO index (both detrended) when the NPO leads the SIE by one month, indicating that the negative phase of NPO leads to a decrease in the Okhotsk SIE. A spatial pattern of regression coefficients of detrended SLP onto Okhotsk SIE confirms that the negative NPO phase is dominantly associated with the Okhotsk SIE reduction. Further, we found that the surface temperature in the Sea of Okhotsk has a strong correlation with the NPO index and with the Okhotsk SIE, with the hottest warming record in 2015 since 1979 even when the long-term trend was removed. To further assess the influence of the NPO, we compared the distributions of Okhotsk SIE between negative and positive NPO phases using CMIP5 multimodel simulations. During negative NPO phases, PDFs shift toward lower Okhotsk 
SIE as investigated in the observation. In contrast, NPO does not have significant long-term trends in observations and forced simulations, suggesting the natural origin of the NPO variability.

Further, we quantified the contributions of ALL (anthropogenic plus natural external forcing) and NPO (internal variability) influences to the amplitude of the 2015 extreme event and the long-term trend. About 56.0\% (13.4\% to $116.3 \%)$ and $24.7 \%$ (14.6\% to $57.7 \%)$ of the 2015 SIE anomaly were attributable to the external forcing and the large negative NPO phase, respectively, and about $86.1 \%(60.6 \%$ to $121.3 \%)$ of the observed linear trend was found to be due to ALL forcing, indicating that anthropogenic influence is largely responsible for the unprecedented 2015 reduction and declining long-term trend in the Okhotsk SIE. Projection results under the RCP8.5 scenario indicate that the Sea of Okhotsk may experience a sea ice-free condition by the late twenty-first century in some models. Although the RCP4.5 scenario simulation does not predict sea ice-free conditions in the twenty-first century, severe reduction is expected in the Okhotsk SIE.

Our study provides new scientific evidence for the anthropogenic influence on the local-scale sea ice melting in the Sea of Okhotsk. We also identified the important role of natural climate variability in the interannual variations of the regional SIE. We also found that most CMIP5 models underestimate the observed sea ice loss trend in the Okhotsk Sea, which means that a similar underestimation may occur in future projections. Therefore, caution needs to be exercised when interpreting future projections based on the models. Nevertheless, understanding the past changes in the regional sea ice cover in the Sea of Okhotsk provides important implications for atmospheric and oceanic conditions and ecosystems, as well as the transportation corridor over the North Pacific.

Acknowledgments. We thank two anonymous reviewers for their constructive comments. This study was supported by the Korea Polar Research Institute under the project of Development and Application of the Korea Polar Prediction System (KPOPS) for Climate Change and Weather Disaster (PE17130). We acknowledge the World Climate Research Programme's Working Group on Coupled Modelling, which is responsible for CMIP, and we thank the climate modeling groups for producing and making available their model output (as listed in Table 1). For CMIP the U.S. Department of Energy's Program for Climate Model Diagnosis and Intercomparison provides coordinating support and led development of software infrastructure in partnership with the Global Organization for Earth System Science Portals.

\section{REFERENCES}

Bindoff, N. L., and Coauthors, 2013: Detection and attribution of climate change: From global to regional. Climate Change 2013. The Physical Science Basis, T. F. Stocker et al., Eds., Cambridge University Press, 867-952.

Cavalieri, D. J., C. L. Parkinson, P. Gloersen, and H. J. Zwally, 1996 (updated yearly): Sea ice concentrations from Nimbus7 SMMR and DMSP SSM/I-SSMIS passive microwave data, version 1. National Snow and Ice Data Center, Boulder, CO, digital media. [Available online at http://nsidc.org/data/ nsidc-0051.html.]

Christidis, N., P. A. Stott, and A. Ciavarella, 2014: The effect of anthropogenic climate change on the cold spring of 2013 in the United Kingdom [in "Explaining Extreme Events of 2013 from a Climate Perspective"']. Bull. Amer. Meteor. Soc., 95 , S79-S82.

Comiso, J. C., C. L. Parkinson, R. Gersten, and L. Stock, 2008: Accelerated decline in the Arctic sea ice cover. Geophys. Res. Lett., 35, L01703, doi:10.1029/2007GL031972.

Di Lorenzo, E., and Coauthors, 2008: North Pacific Gyre Oscillation links ocean climate and ecosystem change. Geophys. Res. Lett., 35, L08607, doi:10.1029/2007GL032838.

Hansen, J., R. Ruedy, J. Glascoe, and M. Sato, 1999: GISS analysis of surface temperature change. J. Geophys. Res., 104, $30997-$ 31 022, doi:10.1029/1999JD900835.

Hegerl, G. C., and Coauthors, 2007: Understanding and attributing climate change. Climate Change 2007: The Physical Science Basis, S. Solomon et al., Eds., Cambridge University Press, $663-745$.

Holland, M. M., and C. M. Bitz, 2003: Polar amplification of climate change in coupled models. Climate Dyn., 21, 221-232, doi:10.1007/s00382-003-0332-6.

Honda, M., K. Yamazaki, H. Nakamura, and K. Takeuchi, 1999: Dynamic and thermodynamic characteristics of atmospheric response to anomalous sea-ice extent in the Sea of Okhotsk. J. Climate, 12, 3347-3358, doi:10.1175/1520-0442(1999)012<3347: DATCOA $>2.0 . C O ; 2$.

Kalnay, E., and Coauthors, 1996: The NCEP/NCAR 40-Year Reanalysis Project. Bull. Amer. Meteor. Soc., 77, 437-471, doi:10.1175/1520-0477(1996)077<0437:TNYRP>2.0.CO;2.

Kimura, N., and M. Wakatsuchi, 2001: Mechanisms for the variation of sea ice extent in the Northern Hemisphere. J. Geophys. Res., 106, 31319-31 331, doi:10.1029/2000JC000739.

Linkin, M. E., and S. Nigam, 2008: The North Pacific Oscillationwest Pacific teleconnection pattern: Mature-phase structure and winter impacts. J. Climate, 21, 1979-1997, doi:10.1175/ 2007JCLI2048.1.

Meier, W. N., J. Stroeve, and F. Fetterer, 2007: Whither Arctic sea ice? A clear signal of decline regionally, seasonally and extending beyond the satellite record. Ann. Glaciol., 46, 428434, doi:10.3189/172756407782871170.

Mesquita, M. D. S., K. I. Hodges, D. E. Atkinson, and J. Bader, 2011: Sea-ice anomalies in the Sea of Okhotsk and the relationship with storm tracks in the Northern Hemisphere during winter. Tellus, 63A , 312-323, doi:10.1111/ j.1600-0870.2010.00483.x.

Min, S.-K., X. Zhang, F. W. Zwiers, and T. Agnew, 2008: Human influence on Arctic sea ice detectable from early 1990s onwards. Geophys. Res. Lett., 35, L21701, doi:10.1029/ 2008 GL035725.

Nakanowatari, T., K. I. Ohshima, and M. Wakatsuchi, 2007: Warming and oxygen decrease of intermediate water in the 
northwestern North Pacific, originating from the Sea of Okhotsk, 1955-2004. Geophys. Res. Lett., 34, L04602, doi:10.1029/2006GL028243.

Ogi, M., Y. Tachibana, and K. Yamazaki, 2004: The connectivity of the winter North Atlantic Oscillation (NAO) and the summer Okhotsk high. J. Meteor. Soc. Japan, 82, 905-913, doi:10.2151/ jmsj.2004.905.

Overland, J. E., and M. Wang, 2007: Future regional Arctic sea ice declines. Geophys. Res. Lett., 34, L17705, doi:10.1029/ 2007GL030808.

Parkinson, C. L., 1990: The impact of the Siberian high and Aleutian low on the sea-ice cover of the Sea of Okhotsk. Ann. Glaciol., 14, 226-229, doi:10.1017/S0260305500008636.

Rogers, J. C., 1981: The North Pacific Oscillation. J. Climatol., 1, 39-57, doi:10.1002/joc.3370010106.

Sasaki, Y. N., Y. Katagiri, S. Minobe, and I. G. Rigor, 2007: Autumn atmospheric preconditioning for interannual variability of wintertime sea-ice in the Okhotsk Sea. J. Oceanogr., 63, 255-265, doi:10.1007/s10872-007-0026-5.

Simizu, D., K. I. Ohshima, J. Ono, Y. Fukamachi, and G. Mizuta, 2014: What drives the southward drift of sea ice in the Sea of Okhotsk? Prog. Oceanogr., 126, 33-43, doi:10.1016/j.pocean.2014.05.013.
Stott, P. A., D. A. Stone, and M. R. Allen, 2004: Human contribution to the European heatwave of 2003. Nature, 432, 610 614, doi:10.1038/nature03089.

Stroeve, J., M. M. Holland, W. Meier, T. Scambos, and M. Serreze, 2007: Arctic sea ice decline: Faster than forecast. Geophys. Res. Lett., 34, L09501, doi:10.1029/2007GL029703.

Tachibana, Y., M. Honda, and K. Takeuchi, 1996: The abrupt decrease of the sea-ice over the southern part of the Sea of Okhotsk in 1989 and its relation to the recent weakening of the Aleutian low. J. Meteor. Soc. Japan, 74, 579-584.

Taylor, K. E., R. J. Stouffer, and G. A. Meehl, 2012: An overview of CMIP5 and the experiment design. Bull. Amer. Meteor. Soc., 93, 485-498, doi:10.1175/BAMS-D-11-00094.1.

Wang, M., and J. E. Overland, 2009: A sea ice free summer Arctic within 30 years? Geophys. Res. Lett., 36, L07502, doi:10.1029/ 2009GL037820.

—_ and - 2012: A sea ice free summer Arctic within 30 years: An update from CMIP5 models. Geophys. Res. Lett., 39, L18501, doi:10.1029/2012GL052868.

Zhang, R., and T. R. Knutson, 2013: The role of global climate change in the extreme low summer Arctic sea ice extent in 2012 [in "Explaining Extreme Events of 2012 from a Climate Perspective"]. Bull. Amer. Meteor. Soc., 94, S23-S26. 